\title{
NOTES
}

\section{Synthesis and Thermal Properties of Polyester Containing Dicyanovinyl Groups in the Main Chain}

\author{
Yun-Seon KIM, Byung-Gu KIM, and Myoung-Seon GoNG \\ Department of Chemistry, Dankook University, \\ Cheonan 330-714, Chungnam, Korea
}

(Received February 24, 1994)

\begin{abstract}
KEY WORDS Thermally Curable Polymer / Thermally Stable Polymer / Dicyanovinyl Group / Enaminonitriles / Polyester /
\end{abstract}

In recent years, new polymers of special physical properties have been developed through the syntheses and studies of thermally stable polymers. The most promising method of synthesis of such polymer is the incorporation of thermal curing function into polymer chain. Among the functional groups, nadimide, acetylenic, biphenylenic, maleimide, styryl, and $\mathrm{N}$-cyanourea are most frequently employed for the preparation of thermally cross-linkable polymers. $^{1,2}$ On heating, they are converted to thermally stable network polymers. The chemical process of network polymer formation usually involves cycloaddition or addition reaction. Although thermal curing mechanisms have not been clearly elucidated, the dicyanovinyl group is a curable function. ${ }^{3-6}$

This study presents new classes of thermally curable polymers based on the dicyanovinyl group, which is useful as a cross-linking agent for various polymers. The introduction of the dicyanovinyl group as an enaminonitrile or enaryloxynitrile moiety enhances the thermal stability through curing in the case of polyurethanes or polyesters. ${ }^{7-9}$ These systems are of special interest since enaminonitrile or enaryloxynitrile groups are readily introduced by copolymerization.

This paper reports the successful synthesis of a new polyesters and copolyesters containing enaminonitrile units as a dicyanovinyl group by reacting common diols and $p$-bis $[1-[N-$ methyl-( $N$-hydroxyethyl)amino $]-2,2$-dicyanovinyl]benzene (2) with terephthaloyl chloride and their thermal properties.

\section{EXPERIMENTAL}

p-Bis [1-[N-methyl-( $N$-hydroxyethyl)amino]-2,2-dicyanovinyl]benzene (2) was synthesized by the method previously reported. ${ }^{8}$ Ethylene glycol, 1,3-propanediol, 1,4-butanediol, 1,6-hexanediol, 1,8-octanediol, hydroquinone, and Bisphenol A were purified by vacuum distillation or recrystallization. Tetrahydrofuran and triethylamine for solution polymerizations were used after distillation over calcium hydride and sodium metal.

${ }^{1} \mathrm{H}$ NMR spectra were recorded on a Bruker Am-300 spectrometer and FT-IR spectra were taken on a Midac spectrophotometer. Thermal analyses of polymers were carried out on a $\mathrm{Du}$ Pont 2100 and a Mettler thermal analyzer with a heating rate of $10^{\circ} \mathrm{C} \mathrm{min}{ }^{-1}$ under nitrogen atmosphere. GPC data were obtained with a Waters HPLC using three columns ( $\mu$-Styragel $10^{2}, 10^{3}$, and $10^{4} \AA$ ) and a UV detector at $254 \mathrm{~nm}$ in tetrahydrofuran and calibrated with polystyrene standards. Inherent viscosities of the polymer solution were measured in a 
Cannon-Ubbelode viscometer in dimethyl formamide (DMF) solvent at $25^{\circ} \mathrm{C}$. The polymer solutions for viscosity measurement were filtered through a micro-porous filter. Elemental analyses were performed with a Yanaco MT-3 CHN-Analyzer.

Preparation of Bis[1-(2-benzoyloxyethyl)-2,2dicyanovinyl]benzene (3)

A solution of $2.0 \mathrm{~g}(5.4 \mathrm{mmol})$ of 2 and $0.64 \mathrm{~g}$ of triethylamine in $20 \mathrm{ml}$ of tetrahydrofuran was placed in a $100 \mathrm{ml}$ of three-necked flask equipped with a dropping funnel, a condensor and a nitrogen inlet. After $1.50 \mathrm{~g}(10.4 \mathrm{mmol})$ of benzoylchloride in $10 \mathrm{ml}$ of freshly distilled tetrahydrofuran were added to the reaction flask for 30 minutes with a flush of nitrogen, the reaction mixture was stirred for 24 hours. The temperature was raised to $70^{\circ} \mathrm{C}$ and maintained for an additional 24 hours. The pale yellow solution was evaporated and the soil crystal was washed with distilled water several times and recrystallized in acetonitrile to give $2.62 \mathrm{~g}$ of the model compound 3 .

3. Yield $85 \% ; \mathrm{mp} 225^{\circ} \mathrm{C}$ (uncorrected).

${ }^{1} \mathrm{H}$ NMR (DMSO- $\left.d_{6}\right): \delta=7.8 \quad(\mathrm{~s}, 4 \mathrm{H}$, aromatic $\mathrm{H}$ 's in 2) $7.6-7.2(\mathrm{~m}, 10 \mathrm{H}, 2$ Ph- $\mathrm{CO}-\mathrm{O}-) .4 .0\left(\mathrm{~m}, 4 \mathrm{H}, 2-\mathrm{O}-\mathrm{CH}_{2}\right)$ and $3.4-3.7\left(\mathrm{~m}, 10 \mathrm{H}, 2-\mathrm{CH}_{2}-\mathrm{N}\left(\mathrm{C}_{3}\right)_{3}\right)$.

IR (KBr): $2980(\mathrm{C}-\mathrm{H}), 2230(\mathrm{C} \equiv \mathrm{N}), 1760$ $(-\mathrm{C}=\mathrm{O}), 1210-1090(\mathrm{C}-\mathrm{O}$ and $\mathrm{C}-\mathrm{N}) \mathrm{cm}^{-1}$.

Anal. Calcd for $\left(\mathrm{C}_{34} \mathrm{H}_{28} \mathrm{~N}_{6} \mathrm{O}_{4}\right)_{n}: \mathrm{C}, 69.86 \%$; H, $4.79 \%$; N, $14.38 \%$. Found: C, $70.01 \%$; H, $4.81 \%$; N, $14.36 \%$.

\section{Representative Polymerization of $\mathbf{2}$ and diol with Terephthaloyl Chloride}

Terephthaloyl chloride $(0.54 \mathrm{~g}, 2.64 \mathrm{mmol})$ dissolved in $10 \mathrm{ml}$ of tetrahydrofuran was added dropwise to a solution of ethylene glycol and 2 (total amount: $2.64 \mathrm{mmol}$ of the two components) in $20 \mathrm{ml}$ of tetrahydrofuran containing $0.64 \mathrm{~g}$ of triethylamine. The reaction mixture was stirred vigorously at room temperature under nitrogen atmosphere for 24 hours and the temperature was raised to $70^{\circ} \mathrm{C}$ and maintained for 24 hours.

When the reaction was completed, viscosity increase was observed and partial precipitation of polymer occurred. After $200 \mathrm{ml}$ of $n$-hexane were added the polymer was isolated by filtration, and washed with water several times.

A similar procedure was applied to prepare other polymers, $4-16$ with different content of 2 and ethylene glycol, 1,3-propanediol, 1,4butanediol, 1,6-hexanediol, 1,8-octanediol, hydroquinone and Bisphenol A.

7. Yield $77 \%$.

${ }^{1} \mathrm{H}$ NMR (dimethyl sulfoxide- $d_{6}$ ): $\delta=8.0$ (s, $4 \mathrm{H},-\mathrm{CO}-\mathrm{Ph}-\mathrm{CO}-), 7.8(\mathrm{~s}, 2 \mathrm{H}, 1 / 2$ aromatic H's in 2), $4.0\left(\mathrm{~m}, 4 \mathrm{H}, 1 / 22-\mathrm{OCH}_{2} \mathrm{CH}_{2}-\right.$ $\mathrm{N}\left(\mathrm{CH}_{3}\right)-$ and $\left.1 / 2-\mathrm{OCH}_{2} \mathrm{CH}_{2}-\mathrm{O}-\right), 3.8-3.4$ (m, 5H, 1/2 $2-\mathrm{CH}_{2} \mathrm{CH}_{2}-\mathrm{N}\left(\mathrm{CH}_{3}\right)-$ ).

IR (KBr): $3020(\mathrm{C}-\mathrm{H}), 2220(\mathrm{C} \equiv \mathrm{N}), 1710$ $(\mathrm{C}=\mathrm{O}), 1580(\mathrm{C}=\mathrm{C}), 1100-1300(\mathrm{C}-\mathrm{N}$ and $\mathrm{C}-\mathrm{O}) \mathrm{cm}^{-1}$.

Anal. Calcd for $\left(\mathrm{C}_{19} \mathrm{H}_{15} \mathrm{~N}_{3} \mathrm{O}_{4}\right)_{n}$ : C, $65.33 \%$; $\mathrm{H}, 4.30 \%$; N, $12.03 \%$. Found: C, $65.25 \%$; H, $4.19 \% ; \mathrm{N}, 12.11 \%$.

10. Yield $81 \%$.

${ }^{1} \mathrm{H}$ NMR (DMSO- $\left.d_{6}\right): \delta=8.0(\mathrm{~s}, 4 \mathrm{H},-\mathrm{CO}-$ $\mathrm{Ph}-\mathrm{CO}-$ ), 7.8 (s, 2H, 1/2 aromatic H's in 2), $4.0-3.8\left(\mathrm{~m}, 4 \mathrm{H}, 2-\mathrm{O}-\mathrm{CH}_{2}-\right), 3.7-3.4(\mathrm{~m}$, $\left.10 \mathrm{H}, 2-\mathrm{CH}_{2} \mathrm{~N}\left(\mathrm{C}_{3}\right)-\right)$.

IR (KBr): $3000(\mathrm{C}-\mathrm{H}), 2210(\mathrm{C} \equiv \mathrm{N}), 1710$ $(\mathrm{C}=\mathrm{O}), 1210-1110(\mathrm{C}-\mathrm{O}-) \mathrm{cm}^{-1}$.

Anal. Calcd for $\left(\mathrm{C}_{28} \mathrm{H}_{22} \mathrm{~N}_{6} \mathrm{O}_{4}\right)_{n}$ : C, $66.40 \%$; $\mathrm{H}, 4.35 \%$; N, $16.60 \%$. Found: C, $66.28 \%$; $\mathrm{H}$, $4.28 \% ; \mathrm{N}, 16.57 \%$.

15. Yield $90 \%$.

${ }^{1} \mathrm{H}$ NMR (DMSO- $d_{6}$ ): $\delta=8.0 \quad(\mathrm{~s}, \quad 4 \mathrm{H}$, - $\mathrm{CH}-\mathrm{Ph}-\mathrm{CO}-$ ), 7.8 (s, 2H, 1/2 aromatic H's in 2), $7.5-6.8(\mathrm{~m}, 4 \mathrm{H}, 1 / 2$ aromatic $\mathrm{H}$ 's in Bisphenol A), $4.1-3.8\left(\mathrm{~m}, 2 \mathrm{H}, 1 / 22-\mathrm{OCH}_{2}-\right)$, $3.7-3.4\left(\mathrm{~m}, 5 \mathrm{H}, 1 / 2-\mathrm{C}_{2} \mathrm{~N}\left(\mathrm{C}_{3}\right)-\right), 1.8(\mathrm{~s}$, $\left.3 \mathrm{H}, 1 / 2-\mathrm{Ph}-\mathrm{C}\left(\mathrm{CH}_{3}\right)_{2}-\mathrm{Ph}-\right)$.

IR (KBr): $3010(\mathrm{C}-\mathrm{H}), 2230(\mathrm{C} \equiv \mathrm{N}), 1720$ $(\mathrm{C}=\mathrm{O}), 1100-1300\left(\mathrm{C}-\mathrm{N}\right.$ and $\mathrm{C}-\mathrm{O}-\mathrm{cm}^{-1}$.

Anal. Calcd for $\left(\mathrm{C}_{24.5} \mathrm{H}_{16} \mathrm{~N}_{3} \mathrm{O}_{4}\right)_{n}$ : C, $70.67 \% ; \mathrm{H}, 3.85 \% ; \mathrm{N}, 10.10 \%$. Found: $\mathrm{C}$, $70.62 \% ; \mathrm{H}, 3.81 \% ; \mathrm{N}, 10.07 \%$. 


\section{RESULTS AND DISCUSSION}

Diol monomer, $p$-bis[1-( $N$-methyl- $(N$-hydroxyethyl)amino]-2,2-dicyanovinyl]benzene (2) was prepared from the reaction of $p$ bis(1-chloro-2,2-dicyanovinyl)benzene (1) with excess $2-(N$-methylamino)ethanol in methylene chloride at room temperature as described previously. $^{8}$

The conditions and feasibility of ester formation were investigated by preparation of the model compound, $p$-bis $[1-(N$-methyl $-(N$ benzoyloxyethyl)amino]-2,2-dicyanovinyl]benzene (3), obtained by reacting 2 with benzoylchloride in the presence of triethylamine in $85 \%$ yield according to Scheme 1 .

The IR spectrum of the model compound exhibited bands at 2230, 1760, 1580, and $1300-1100 \mathrm{~cm}^{-1}$ assignable to $\mathrm{C} \equiv \mathrm{N}, \mathrm{C}=\mathrm{O}$, $\mathrm{C}=\mathrm{C}$, and $\mathrm{C}-\mathrm{O}$ stretching absorption. In the NMR spectrum, the aromatic peaks of 2 and benzoate appeared at 7.8 and $7.5-8.2 \mathrm{ppm}$, respectively. The aliphatic protons attached to oxygen and nitrogen were shown as broad multiplets between 3.0 and $4.4 \mathrm{ppm}$. On the basis of these results, the model compound is presumed to be an enaminonitrile containing ester moiety.

The polymerizations of different contents of 2 and ethylene glycol with terephthaloyl chloride were conducted to obtain controlled amounts of enaminonitrile units in the main chain of polyesters.

Polyesters and copolyesters were prepared with 2 and ethylene glycol in the following mole

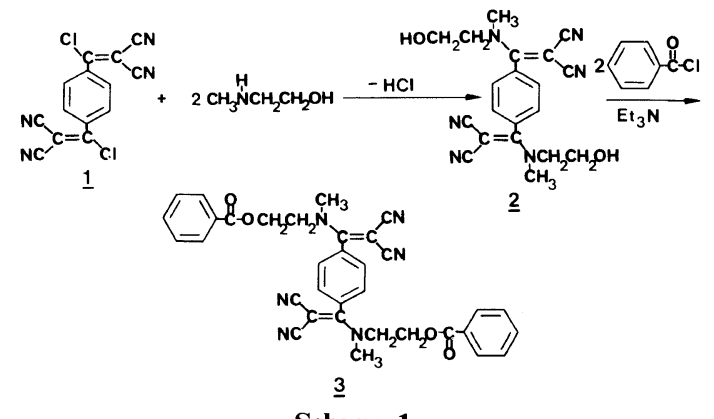

Scheme 1. ratios: $0 / 1,1 / 4,1 / 2,1 / 1,2 / 1,4 / 1$, and $1 / 0$. Copolyesters containing enaminonitriles units were also obtained from 1,3-propanediol, 1,4butanediol, 1,6-hexanediol, 1,8-octanediol, hydroquinone, and Bisphenol $\mathrm{A}$ with terephthaloyl chloride in Scheme 2.

The results and conditions of copolymeriza-

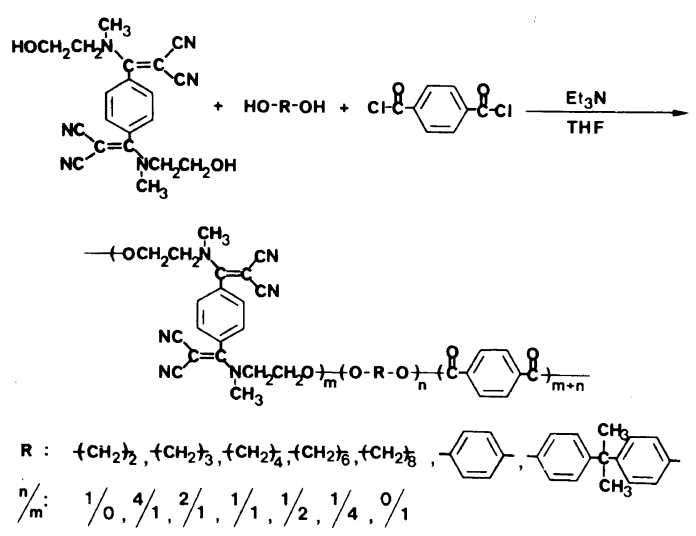

Scheme 2.

Table I. Results and conditions of the polymerization of $\mathbf{2}$ and diol with terephthaloyl chloride

\begin{tabular}{|c|c|c|c|c|c|}
\hline Polymer $^{\mathrm{a}}$ & Diol $^{b}$ & Diol : 2 & $\frac{\text { Yield }}{\%}$ & $M_{w}^{\mathrm{c}}$ & $\eta_{\mathrm{inh}}^{\mathrm{d}}$ \\
\hline 4 & ED & $1: 0$ & 80 & - & - \\
\hline 5 & EG & $5: 1$ & 76 & 12000 & 0.12 \\
\hline 6 & EG & $2: 1$ & 81 & 14500 & 0.11 \\
\hline 7 & EG & $1: 1$ & 77 & 10600 & 0.11 \\
\hline 8 & EG & $1: 2$ & 89 & 15000 & 0.21 \\
\hline 9 & EG & $1: 4$ & 91 & 13700 & 0.17 \\
\hline 10 & EG & $0: 1$ & 81 & 17000 & 0.19 \\
\hline 11 & 1,3-PD & $1: 1$ & 95 & 11500 & 0.12 \\
\hline 12 & 1,4-BD & $1: 1$ & 95 & 13500 & 0.17 \\
\hline 13 & 1,6-HD & $1: 1$ & 98 & 12000 & 0.13 \\
\hline 14 & $1,8-\mathrm{OD}$ & $1: 1$ & 98 & 11100 & 0.12 \\
\hline 15 & HQ & $1: 1$ & 92 & 12000 & - \\
\hline 16 & BPA & $1: 1$ & 90 & 12500 & - \\
\hline
\end{tabular}

${ }^{\text {a }}$ Polymerizations were performed in tetrahydrofuran for 48 hours in all cases.

${ }^{b}$ EG, ethyleneglycol; 1,3-PD, 1,3-propanediol; 1,4-BD, 1,4-butanediol; 1,6-HD, 1,6-hexanediol; 1,8-OD, 1,8octanediol; HQ, hydroquinone; BPA, Bisphenol A.

c Weight average molecular weights were obtained in tetrahydrofuran solvent.

d Measured in $N, N$-dimethylformamide in $1 \mathrm{~g} \mathrm{dl}^{-1}$ at $25^{\circ} \mathrm{C}$. 
tion are summarized in Table I. The solution polymerization resulted in white powdery polyesters in high conversion in all cases. The chemical structures of the polyesters were characterized by spectroscopy and matched well with the model compound.

In the IR spectrum of copolyester, 7 with equimolar ratio of $\mathbf{2}$ and ethylene glycol, the characteristic bands at 2220,1710,1580, and $1300-1100 \mathrm{~cm}^{-1}$ attributable to $\mathrm{C} \equiv \mathrm{N}, \mathrm{C}=\mathrm{O}$, $\mathrm{C}=\mathrm{C}$, and $\mathrm{C}-\mathrm{O}$, respectively, appeared.

In the ${ }^{1} \mathrm{H}$ NMR spectrum, the aromatic protones of fragment of 2 appeared at $7.6 \mathrm{ppm}$ as a singlet, whereas those of terephthalate, at $8.0 \mathrm{ppm}$.

The NMR integration ratio of two monomer units in the copolymers were variable according to the ratio of monomer in the feed. Thus, the integration of the peak at $4.1 \mathrm{ppm}$ assignable to methylene protons attached to ester bond increased with the content of ethylene glycol

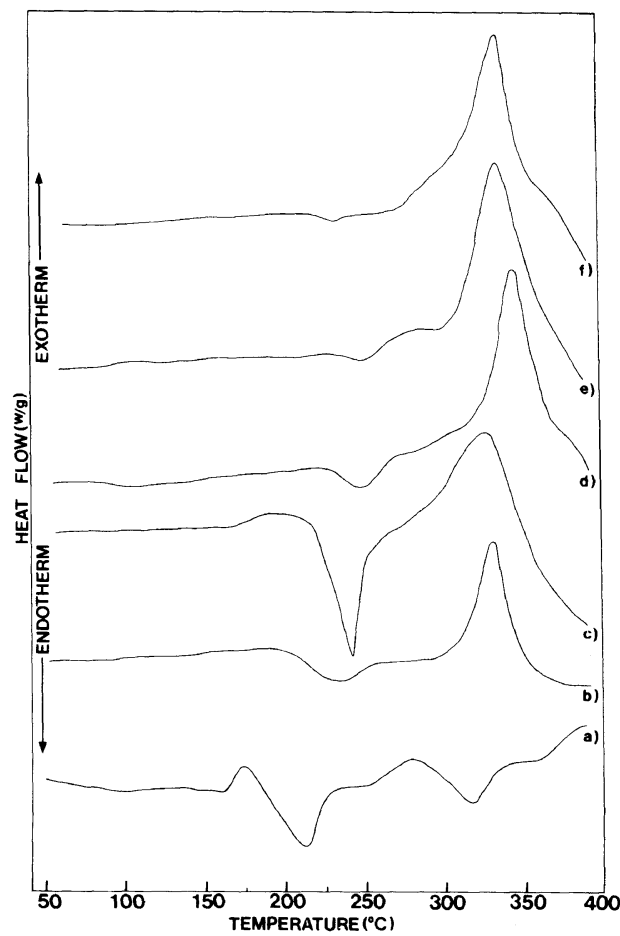

Figure 1. DSC thermogram of polyesters, a) 4, b) 6, c) 7,d) 8, e) 9, and f) 10 obtained from 2 and ethylene glycol with tetrephthaloyl chloride under nitrogen. in the polymer chain. The polymer with more content of 2 showed a stronger band at 2210 $\mathrm{cm}^{-1}$ attributable to nitrile group in the IR spectrum. These results were also confirmed by elemental analyses.

The copolyesters containing enaminonitrile units were soluble in polar aprotic solvents such as DMF, dimethyl sulfoxide (DMSO), dimethylacetamide (DMAc), and $N$-methylpyrollidone (N-MP), and even soluble in 1,2dichloroethane and tetrahydrofuran. The solubility of copolyester derived from Bisphenol A and hydroquinone in DMF and DMSO decreased apparently because of rigid structure of the aromatic moiety. As the amount of $\mathbf{2}$ in the polymer increased, solubility in DMF increased.

However, homopolyester composed only of ethylene glycol or $\mathbf{2}$ was insoluble in such a solvent. The increased solubility of other copolyesters in common organic solvents is mainly due to the incorporation of the

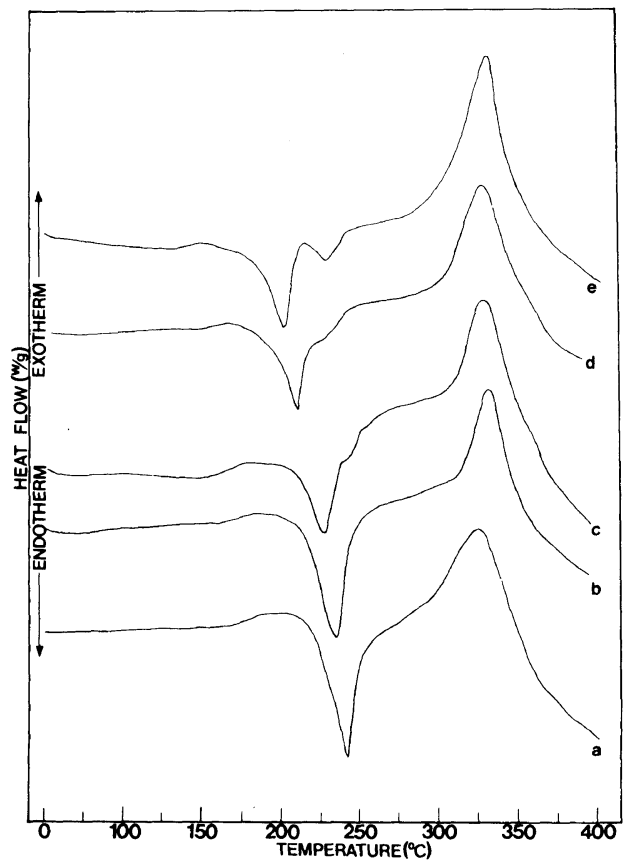

Figure 2. DSC thermograms of copolyesters, a) 7, b) 11, c) 12, d) 13, and e) 14 obtained from 2 and various diols with terephthaloyl chloride. 


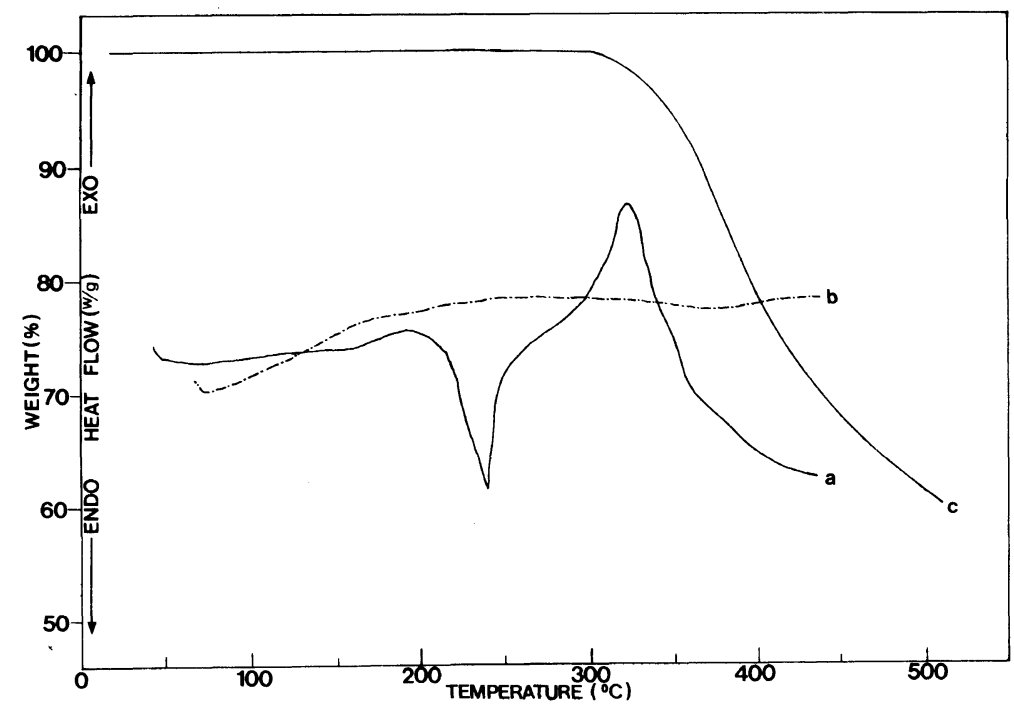

Figure 3. DSC thermograms, a) 1st scan, b) 2nd scan, and c) TGA traces of copolyester, 7 obtained from equimolar ratio of $\mathbf{2}$ and ethylene glycol with terephthaloyl chloride.

enaminonitriles moiety into the polyesters. When the polymers were heated at $320^{\circ} \mathrm{C}$, the polymers were no longer soluble in the solvents for untreated polymers. This indicates that the polymers were changed in chemical structure during heating.

The polymers have inherent viscosities of $0.1-0.2 \mathrm{dlg}^{-1}$ with $\mathrm{Mn}$ in the range of $4000-5600$ and $M_{w}$ in the range of 12000 15000. Although the polyesters are not of high molecular weight judging from the viscosity and GPC data, hard films were cast from DMF solution.

In DSC thermograms as shown in Figures 1 and 2, copolyester 8, 9, and 10 with higher content of $\mathbf{2}$ showed no endotherm, while the copolyester 7 with lower content of $\mathbf{2}$ showed endotherm attributable to melting of polymer at $242^{\circ} \mathrm{C}$.

The homopolyester of $\mathbf{2}$ shows only a large exotherm, which corresponds to changes in chemical structure, followed by decomposition.

On the other hand, polymers incorporated with other diols such as 1,3-propanediol, 1,4butanediol, 1,6-hexanediol, and 1,8-octanediol,

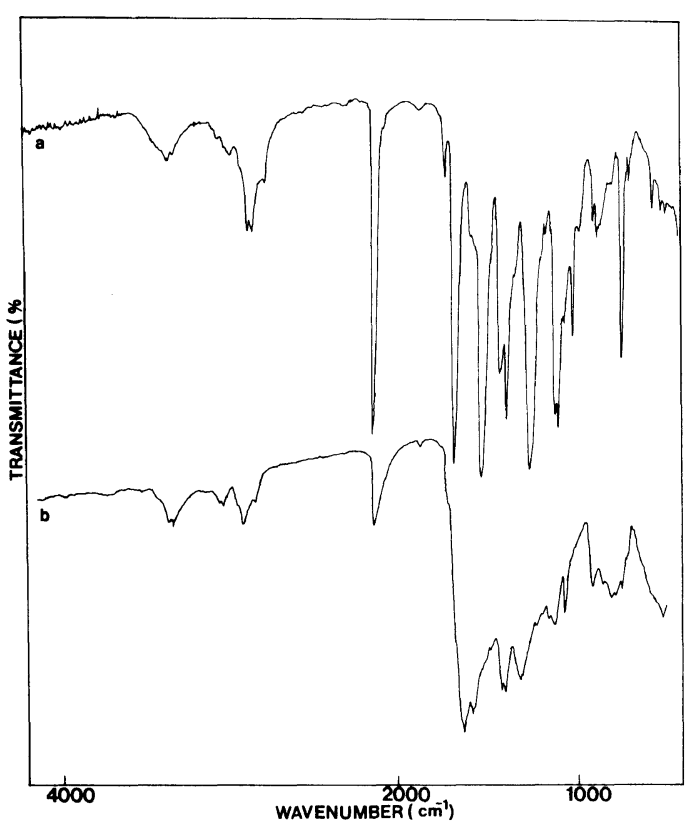

Figure 4. FT-IR spectra of polyester, 7 a) before and b) after curing $310^{\circ} \mathrm{C}$ for $1 \mathrm{~h}$ under nitrogen.

the clear endotherm appeared between 220 $250^{\circ} \mathrm{C}$ as shown in Figure 2. The endotherm attributable to the melting temperature decreased regularly as the length of flexible 
alkylenic chain increased.

Most copolyesters containing enaminonitrile units showed a exotherm beginning at around $310^{\circ} \mathrm{C}$. The exothermic peak disappeared upon cooling and rescanning the sample as exhibited in Figure 3(b), which may be due to change in chemical structure of polymer in the course of heating to $320^{\circ} \mathrm{C}$. At the beginning of an exothermic temperature of $310^{\circ} \mathrm{C}$, slight loss of weight was observed as exhibited in Figure 3(a) of DSC and 3(c) of TGA. Examination of the IR spectra of a sample of cured or uncured at $310^{\circ} \mathrm{C}$ for 1 hour showed that the bands at
2957 and $2212 \mathrm{~cm}^{-1}$ corresponding to $\mathrm{C}-\mathrm{H}$ and $\mathrm{C} \equiv \mathrm{N}$ stretching have reduced apparently and bands at 1721 and $1558 \mathrm{~cm}^{-1}$ broadened as shown in Figure 4.

The curing of the dicyanovinyl group thus obviously occurs. At the temperature of the highest peak of the exotherm at around $330^{\circ} \mathrm{C}$, the weight loss was within $6 \%$ of their mass and decomposition of alkylenic unit of polymer accelerated.

Thermal stability data are listed in Table II and TGA traces are shown in Figure 5. The polymers showed a $10 \%$ weight loss in ni-

Table II. Thermal properties of polyesters containing enaminonitrile units

\begin{tabular}{|c|c|c|c|c|c|c|c|}
\hline \multirow{2}{*}{ No. } & \multirow{2}{*}{$T_{\mathrm{g}}$} & \multirow{2}{*}{$\frac{\text { Endo }}{{ }^{\circ} \mathrm{C}}$} & \multirow{2}{*}{$\frac{\text { Exo }}{{ }^{\circ} \mathrm{C}}$} & \multirow{2}{*}{$\frac{10 \% \text { wt loss }}{{ }^{\circ} \mathrm{C}}$} & \multicolumn{3}{|c|}{ Residual weight $/ \%$} \\
\hline & & & & & $300^{\circ} \mathrm{C}$ & $400^{\circ} \mathrm{C}$ & $500^{\circ} \mathrm{C}$ \\
\hline 4 & - & 212 & 287 & 367 & 96 & 78 & 20 \\
\hline 5 & 241 & 363 & - & 330 & 92 & 74 & 24 \\
\hline 6 & 142 & - & 332 & 350 & 98 & 77 & 60 \\
\hline 7 & 175 & 242 & 325 & 365 & 99 & 74 & 61 \\
\hline 8 & - & - & 345 & 370 & 97 & 77 & 62 \\
\hline 9 & - & - & 330 & 368 & 99 & 82 & 63 \\
\hline 10 & 258 & - & 325 & 342 & 97 & 86 & 70 \\
\hline 11 & 165 & 231 & 330 & 360 & 97 & 63 & 55 \\
\hline 12 & 165 & 226 & 327 & 363 & 98 & 60 & 50 \\
\hline 13 & - & 213 & 325 & 375 & 98 & 85 & 50 \\
\hline 14 & - & 208 & 330 & 362 & 98 & 70 & 49 \\
\hline 15 & - & 238 & 335 & 342 & 98 & 72 & 71 \\
\hline 16 & - & 213 & 313 & 365 & 96 & 72 & 59 \\
\hline
\end{tabular}

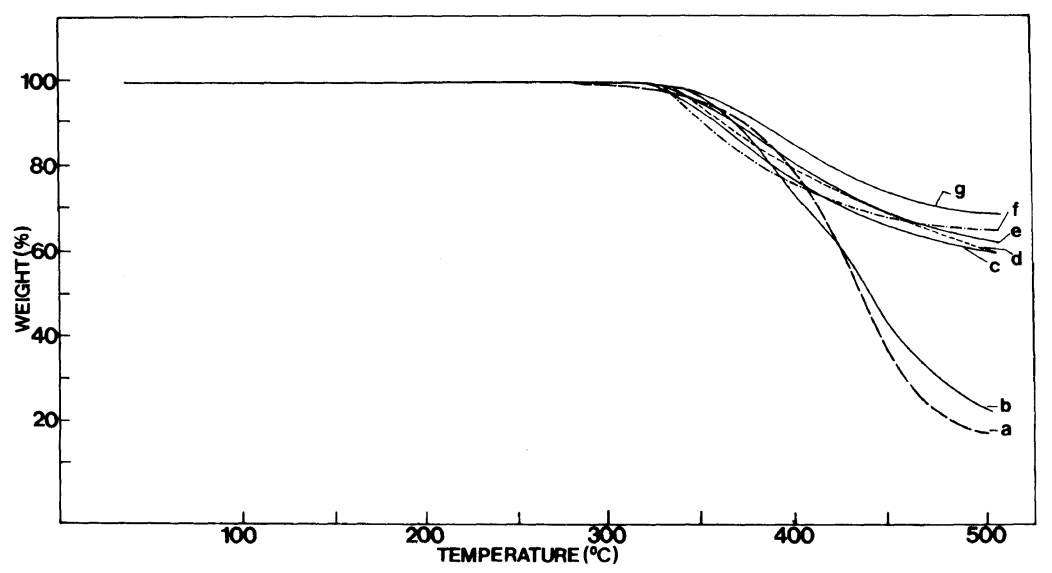

Figure 5. Thermogravimograms of polyesters, a) 4, b) 5, c) 6, d), 7, e) 8, f) 9, and g) 10 obtained from 2 and ethylene glycol with terephthaloyl chloride. 
trogen over a temperature of $350-380^{\circ} \mathrm{C}$ and gave a residual weight varing from 50 to $70 \%$ at $500^{\circ} \mathrm{C}$. But the homopolyester, 4 and copolyester, $\mathbf{5}$ with lower content of $\mathbf{2}$ showed $20-25 \%$ residual weight at $500^{\circ} \mathrm{C}$. The higher content of enaminonitrile units in polymer showed greater thermal stability than those with higher content of ethylene glycol. This thermal stability was related to the content of the dicyanovinyl group in the polymer chain.

Insolubility in solvent after curing, disappearance of an exotherm during 2nd scanning of DSC, reduction of nitrile band in IR spectra and enhancement of thermal stability are evidence of inter- or intramolecular addition or cross-linking reactions of the dicyanovinyl group.

\section{REFERENCES}

1. P. E. Cassidy, "Thermally Stable Polymers-Syntheses and Properties," Marcel Dekker Inc., New York, N.Y., 1981, p 288.

2. H. J. Spinelli and F. W. Harries, "Reactive Oligomers," ACS Symp. Ser. 282, Am. Chem. Soc., Washington, D.C., 1985, pp 1-115.

3. J. A. Moore and D. R. Robello, Macromolecules, 22 , 1084 (1989).

4. J. A. Moore and P. G. Mehta, Polym. Mater. Sci. Eng., 63, 351 (1990).

5. M. S. Gong, H. S. Moon, and S. T. Kim, Makromol. Chem., Rapid Commun., 12, 591 (1991).

6. M. S. Gong, H. S. Moon, and C. B. Kim, Polym. J., 25, 193 (1993).

7. M. S. Gong, S. T. Kim, J. S. Kim, and S. H. Choi, Polym. J., 25, 763 (1993).

8. M. S. Gong, S. T. Kim, and H. S. Moon, Macromolecules, 25, 7392 (1992).

9. M. S. Gong, B. G. Kim, H. G. Cho, and S. H. Choi, Macromolecules, 26, 6654 (1993). 